\title{
Zakat: Katup Pengaman Keseimbangan Kehidupan Ekonomi Umat
}

\author{
Anis Tyas Kuncoro* \\ Universitas Islam Sultan Agung (UNISSULA), Semarang \\ Email: anieskuncoro982@gmail.com
}

\begin{abstract}
Indeed, the teachings of Islam with the concept of zakah has provided a fundamental foundation for the growth and development of socioeconomic power of society. This teaching has a complex dimension that is not shared by religious teachings or other classical or modern schools of economic thought. From the standpoint of ideology and belief, at least, zakah has given a fundamental view of the position of property and possession. From the point of view of the development of social welfare, zakah is one of the instruments of equal distribution of income and welfare, because with good zakah management will enable the sustainability of development and economic growth which if simultaneously coupled with income equality, economic growth equality. This study uses descriptive method of analysis by referring to some references on zakah both from government regulations and contemporary books on zakah. The result of this study is in order to achieve equitable distribution of economic growth of society, the improvement of systematic zakah governance is considered very strategic. In this case the role of government can play its role in improving the management of zakah among Muslims maximally by using a repressive and systematic approach, so that the economic growth of the community will grow thoroughly.
\end{abstract}

Keywords: Value of Philanthropy, Istikhlaf, Ibadah al-Mãliyah alIjtimā'iyyah.

* Dosen Jurusan Syariah, Fakultas Agama Islam, UNISSULA. 
74 Anis Tyas Kuncoro

\section{Abstrak}

Sesungguhnya ajaran Islam dengan konsep zakatnya telah memberikan landasan mendasar bagi pertumbuhan dan perkembangan kekuatan sosial ekonomi umatnya. Ajaran ini memiliki dimensi yang kompleks yang tidak dimiliki oleh ajaran agama atau aliran-aliran pemikiran ekonomi klasik maupun modern lainnya. Dari sudut pandang ideologi dan keyakinan, paling tidak, zakat telah memberikan pandangan fundamental terhadap kedudukan harta dan kepemilikan. Sedang dari sudut pandang pembangunan kesejahteraan sosial, zakat merupakan salah satu instrumen pemerataan distribusi pendapatan dan kesejahteraaan, karena dengan pengelolaan zakat yang baik akan memungkinkan keberlangsugnan pembangunan dan pertumbuhan ekonomi yang jika sekaligus dibarengi dengan pemerataan pendapatan, economic growth equality. Studi ini menggunakan metode deskriptif analisis dengan merujuk kepada beberapa referensi mengenai zakat baik dari peraturan pemerintah dan buku-buku kontemporer mengenai zakat. Hasil dari studi ini adalah dalam rangka tercapainya pemerataan pertumbuhan ekonomi masyarakat, peningkatan tata kelola zakat yang sistematis dirasa sangat strategis. Dalam hal ini peran pemerintah dapat memerankan fungsinya dalam meningkatkan tata kelolaan zakat dikalangan umat Muslim secara maksimal dengan menggunakan pendekatan yang represif dan sistematik sehingga pertumbuhan ekonomi masyarakat akan tumbuh secara menyeluruh.

Kata kunci: Nilai Filantropi, Istikhlaf, Ibadah Māliyah al- Ijtimāciyyah.

\section{Pendahuluan}

unculanya pemikiran ekonomi Islam merupakan
wujud usaha nyata masyarakat muslim dalam upaya
memperbaiki tatanan perekonomian dunia yang kurang baik pada eknomi kapitaslis pasca keruntuhan ekonomi sosialis dan menjadikannya sebagai model alternatif pilihan yang dapat merubah paradigma dan budaya masyarakat dunia, tidak terkecuali masyarakat muslim Indonesia, dalam pembangunan ekonomi yang seiring dengan program yang telah dijalankan pemerintah guna mengatasi dampak krisis ekonomi dalam rangka pembangunan kualitas manusia, 
Zakat: Katup Pengaman Keseimbangan ... $\mid 75$

khususnya dalam hal penanggulangan kemiskinan. Dalam hal ini, realitas struktur zakat adalah merupakan pilihan tepat dalam mengakomodir konsep pembangunan yang berkelanjutan dan berkeadilan sesuai dengan tujuan pembangunan ekonomi Indonesia yang sebenarnya, yaitu pemanfaatan sumber daya yang sebesar-besarnya untuk kesejahteraan rakyat. Mengingat struktur zakat dalam kegiatan eknomi mengandung dimensi teologis, individual dan sosial yang mampu meberikan nilai tambah yang tidak dimiliki oleh sistem ekonomi lainnya.

Dalam Islam, tujuan yang hendak dicapai, dalam konteks apapun, tidak dapat dipisahkan dari ideologi dan keyakinan. Karena yang demikian akan memberikan dorongan kuat bagi setiap manusia untuk mendayagunakan eksistensi dan potensi dirinya sebagai khalifatullah di bumi (QS. 2: 30), utamanya dalam pemanfaatan dan pengelolaan harta, sehingga memunculkan dimensi horizontal Islam yang menuntut terwujudnya tatanan sosial yang bernafaskan keadilan dan kesejahteraaan individu sekaligus orang lain, terutama kaum fakir miskin dan anak-anak terlantar.

Dalam tantanan dimikian, setiap individu mendapat perlakuan sama (egaliter) dan menjunjung tinggi nilai-nilai solidaritas sosial, lepas dan bebas dari egoisme, ketamakan dan keserakahan. Oleh karenya, ada hal yang mendasar yang harus senantiasa digaris bawahi dan ditekankan kepada seluruh para ahli dan praktisi di bidang ekonomi bahwa konsep kepemilikan harta dalam ajaran Islam secara tegas sekali menolak konsep kepemilikan tanpa batas sebagaimana dianut dalam sistem kapitalisme atau sebaliknya penghapusan total institusi kepemilikan individu dibawah sistem sosialisme.

Tidak sedikit memang peran sistem kapitaslisme atau sosalisme dengan konsep kepemilikan hartanya dalam bidang pembangunan ekonomi. Namun tidak sedikit pula keterpurukan dan kerusakan yang menimpa peradaban dunia 
76 | Anis Tyas Kuncoro

yang diakibatkan penekanan berlebihan kedua sistem ersebut terhadap nilai-nilai material dan mengabaikan pandangan mendasar tentang esensi manusia sebagai khalifatullah, yang mengemban amanah pengelolaan dan pemanfaatan alam semesta secara adil dan berimbang.

\section{Manusia Berjiwa Altruistik}

Dalam hal ini, al-Qur'an telah menandaskan bahwa status individu yang secara ekonomi baik tidak akan menjamin kebahagiaan tanpa dibarengi terciptanya kondisi sosial yang harmonis. Begitupun sebaliknya, kondisi sosial yang baik, stabil dan tanpa gejolak tidak otomatis menjamin kebahagiaan yang utuh bila kondisi individunya dilanda kemiskinan dan kepapaan. Keduanya harus seimbang, dan untuk mewujudkan keseimbangan dimaksud diperlukan suatu pendekatan yang berorientas pada hal-hal yang lebih tinggi dari sekedar orientasi nilai-nilai material, yakni orientasi nilai-nilai spiritual (QS. 18: 46) sehingga terbentuk kerangka normatif perilaku berekonomi yang sesuai dengan al-Qur'an dan Hadis.

Setiap individu muslim senantiasa diarahkan untuk berperilaku sesuai dengan norma-norma yang bersumberkan alQur'an dan Hadis, tak terkecuali dalam aktifitas berekonomi. Yang demikian ditujukan untuk membentuk setiap individu menjadi homo Islamcus yang memiliki tanggungjawab sosial, apalagi mengingat dalam tataran realitas memang ditujukan bahwa setiap orang memiliki kapasitas berbeda dalam segala hal, tidak terkecuali dalam kepemilikan harta, sesuai dengan kontribuasi kerja dan kapasitas intelektualnya. Islam dengan norma istikhlafnya. Memandang bahwa perbedaan tersebut adalah merupakan harmonisasi tatanan kehidupan global dan bukan sesuatu yang harus saling dipertentangkan atau saling dihadap-hadapkan, karena konsep dasar yang diusung adalah bawah kepemilikan harta adalah suatu amanah yang mengandung tanggungjawab yang harus ditunaikan. Konsep

ulul albab: Jurnal Studi dan Penelitian Hukum Islam 
amanah ini memberikan arti bahwa kepemilikan individu atas harta kekayaan harus bebas dari sikap mementingkan diri sendiri dan ketamakan yang berlebihan serta hal tersebut dirancang sejalan dengan kesejahteraan sosial. ${ }^{1}$

Dalam penerapannya, setiap individu muslim dalam aktifitas produksinya akan dituntut untuk mendapatkan keuntungan yang sebanyak-sebanyaknya dengan tetap memperhatikan kepentingan orang lain seperti adil dalam memenuhi upah pekerja sebagai haknya, larangan monopoli dan ihtikar (penimbunan barang guna memperoleh keuntungan lebih) ataupun kolusi yang merugikan orang banyak serta pengelolaan sumber daya terlarang seperti prkatek prostitusi, ilegal loging dan jual beli minuman keras.

Disamping itu ada pula, dalam aktifitas konsumsi, setiap individu muslim dituntut untuk menjauhi perilaku tabdzir (pemborosan), meminum khamar, menggunakan narkoba dan segal seuatu yang merusak diri sendiri dan orang lain. Hal utama dalam penerapan konsep ini adalah senantiasa memelihara dan membangun solidaritas sosial yang mampu menigkatkan taraf hidup masyarakat yang tergolong kurang mampu dengan menghidupkan nilai-nilai filantopi Islam seperti zakat, infak, shadaqah, wakaf, dan lain-lain.

Dengan begitu, orientasi manusia dimasa mendatang dalam menata kehidupan ekonominya akan senantiasa dilandaskan pada suatu pandangan dan model yang memasukan pertimbangan nilai keadilan, keadilan yang bukan lagi berdimendsi "angka" melainkan juga berdimensi "rasa" dan kebutuhan kemanusiaan.

${ }^{1}$ Syed Nawah Haedar Naqvi, Menggagas Ilmu Ekonomi Islam, terj. M. Saiful Anam dan M. Ufuqil Mubin, (Yogyakarta: Pustaka Pelajar, 2003), cet. Ke$1,120$. 
$78 \mid$ Anis Tyas Kuncoro

\section{Urgensi Zakat dalam Ajaran Islam}

Menunaikan zakat adalah kewajiban bagi umat Islam yang mampu. Zakat adalah merupakan salah satu rukun dari rukun Islam yang lima sebagai ibadah kepada Allah sekaligus merupakan amal sosial (kemasyarakatan) dan kemanusiaan dalam wujud mengkhususkan sejumlah harta atau nilai milik perorangan atau badan hukum untuk diberikan kepada yang berhak dengan syarat-syarat tertentu guna menyucikan dan menumbuhkan harta serta jiwa pribadi para wajib zakat, mengurangi penderitaan masyarakat, memelihara keamanan dan meingkatkan pembangunan. ${ }^{2}$

Demikian pentingnya ibadah ini, Islam telah menempatkan sebagai pilar ketiga setelah ibadah shalat. Dan dalam al-Qur'an, Alalh telah menyebutkan perihal zakat selalu berdampingan dengan kewajiban shalat. Ini menunjukan bahwa keduanya mempunyai arti yang urgen dan memiliki hubungan erat dalam menumbuh kembangkan kualitas hidup umat. Shalat merupakan ibadah jasmaniah yang paling utama, sedang zakat dipandang sebagai ibadah maliyah (harta benda) yang paling mulia. Keharmonisan antara keduanya mutlak diwujudkan sehingga dapat membangun tatanan sosial yang solid, berbasis pada keseimbangan nilai-nilai religi dan ekonomi.

Sesungguhnya ajaran Islam dengan konsep zakatnya telah memberikan landasan mendasar bagi pertumbuhan dan perkembangan kekuatan sosial ekonomi umatnya. Ajaran ini memiliki dimensi yang kompleks yang tidak dimiliki oleh ajaran agama atau aliran-aliran pemikiran ekonomi klasik maupun modern lainnya sehingga dari sisi pembangunan kesejahteraan umat, ada banyak pandangan konstruktif tentang peran, fungsi dan potensi zakat, antara lain:

2 BAZIS DKI Jakarta, Pedoman Pelaksanaan Zakat, Hasil Penelitian dan Seminar Zakat DKI, (Jakarta: BAZIS DKI, 1978), Cet. Ke-2, XII.

ulul albab: Jurnal Studi dan Penelitian Hukum Islam 
Zakat: Katup Pengaman Keseimbangan ... $\mid 79$

1. Zakat yang dikelola dengan baik, dimungkinkan dalam membangun pertumbuhan ekonomi sekaligus pemerataan pendapatan (economy growth with equality). ${ }^{3}$

2. Zakat cenderung pada pendistribusian harta secara egaliter dan menjaga sirkulasi peredarannya. ${ }^{4}$

3. Zakat adalah merupakan sumber kas perbendaharaan negara sekaligus merupakan sokoguru dari kehidupan ekonomi yang telah dicanangkan al-Qur'an. ${ }^{5}$

4. Zakat akan mencegah terjadinya akumulasi dan sentralisasi kepemilikan harta pada segelintir orang dan pada saat yang bersamaan akan mendorong manusia untuk melakukan pengembangan harta (investasi) dan menggalakkan distribusi. ${ }^{6}$

5. Zakat merupakan ibadah maliyah ijtima'iyyah yang memiliki posisi strategis penting dan menentukan. ${ }^{7}$

6. Hikmah diperintahkan kewajiban zakat atas kepemilikan harta kekayaan adalah untuk mendorong aktifitas ekonomi, perputaran modal sekaligus mengurangi aktifitas spekulasi dan penimbunan barang (ihtikar). ${ }^{8}$

3 A. Ilyas Islmail, "Sabar dan Syukur", dalam Rubrik Hikmah Harian Umum Republika, tanggal 23 Mei 1998.

${ }^{4}$ A. Muflih Saifuddin, Pengelolaan Zakat ditinjau dari Aspek Ekonomi, (Bontang: Badan Dakwah Islamiyyah, 1986), Cet. Ke-1, 33.

5 Monzer Kahf, Ekonomi Islam: telaah Analitik terhadap Fungsi Sistem Ekonomi Islam, terj. Machnun Husein, (Yogyakarta: Aditya Media, 2000), Cet. Ke-1, 88.

6 Mustaq Ahmad, Etika Bisnis dalam Islam, terj. Samson Rahman, (Jakarta:; Pustaka al-Kautsar, 2001), cek. Ke-1, 75.

7 Yusuf Qordhowi, al-Ibadah fi al-Islam, (Beirut: Muassasah Risalah, 1993), 235.

8 M. Umer Chapra, The Future of Economics: an Islamic Perspective, (Leicester: the Islamic Foundation, 2000), 313.

Vol. 1, No. 1, Oktober 2017, 73-87 
$80 \mid$ Anis Tyas Kuncoro

\section{Manajamen Zakat}

Kedudukan zakat sebagai ibadah yang memiliki dimensi finansial dan sosial jelas sangat penting, strategis dan menentukan, baik dari sudut pandang ideologi dan keyakinan maupun dari sudut pandang pembangunan kesejahteraan sosial. Dari sudut pandang ideologi dan keyakinan, paling tidak, zakat telah memberikan pandangan fundamental terhadap kedudukan terhadap kedudukan harta dan kepemilikan bahwa kecukupan materi hanya ditempatkan sebagai alat dan bukan tujuan. Sedang dari sudut pandang pembangunan kesejahteraan sosial, zakat merupakan salah satu instrument pemerataan distribusi pendapatan dan kesejahteraan, karenanya dengan pengelolaan zakat yang baik akan memungkinkan keberlangusnan pembangunan dan pertumbuhan ekonomi yang juga sekaligus dibarengi dengan pemerataan pendapatan (economic growth equality). ${ }^{9}$

Lebih dari itu, menurut Sayyid Sabiq, bahwa ditinjau dari perspektif ekonomi, pengelolaan zakat yang baik akan memainkan peran dan fungsi strategis, yaitu pertama, sebagai pilar kebersamaan antara orang-orang yang berkecukupan dengan mereka yang serba kekurangan, karena zakat menjadi perwujuan konkrit dan jaminan sosial yang disyariatkan oleh ajaran Islam; kedua, sebagai salah satu instrument pengentasan kemiskinan; dan ketiga, sebagai sumber dana bagi pembangunan saran dan prasarana umat. ${ }^{10}$

Demikian urgennya peran yang dapat dimainkan, maka sesungguhnya zakat menurut ajaran Islam harus diorganisir dalam suatu wadah atau institusi kelembagaan yang diselenggarakan oleh negara atau pemerintah sebagai pemegang kekuasaan, sebagimana tergambar dalam sejarah peradaban Islam, mulai dari masa kekhalifahan Abu Bakar sebagai peletak

\footnotetext{
${ }^{9}$ M. Umar Chaptra, The Future of Economic ..., 313.

10 Sayyid Sabiq, Fiqh al-Sunnah, (Kuwait: Daar al-Bayan: 1968), 146.
}

ulul albab: Jurnal Studi dan Penelitian Hukum Islam 
aturan dasar pelaksanaan, regulasi dan sistem dalam pemungutan zakat hingga pada masa kekhalifahan Umar bin Abdul Aziz yang telah melengkapi aspek-aspek pengelolaan zakat sebagai sebuah sistem yang aplikatif dalam menggapai tujuan ekonomi. ${ }^{11}$

Namun seiring dengan perkembangan zaman yang dibarengi pula dengan perubahan tatanan sosial serta tuntutan perwujudan kesejahteraan dan keadilan sosial, disamping semakin kompleksnya bidang kehidupan yang menjadi tanggungjawab negara, nampak bahwa dikalangan masyarakat luas banyak sekali usaha-usaha yang ditujukan untuk mewujudkan pengembangan pengelolaan zakat yang baik sehingga timbul inisiatif untuk mendirikan lembaga amil zakat.

Mobilisasi zakat secara kelembagaan, baik oleh pemerintah ataupun masyarakat, lebih banyak mendatangkan manfaat daripada dibayarkan langsung oleh muzakki kepada mustahik. Beberapa manfaat dimaskud, antara lain adalah:

1. Kepastian muzakki dalam membayar zakat.

2. Menghilangkan rasa rendah diri di kalangan mustahik.

3. Efisiensi dan efektifitas pengumpulan penyaluran zakat.

4. Syiar Islam. ${ }^{12}$

5. Zakat yang diperuntukan bagi kepentingan umum seperti fisabilillah, dapat disalurkan dengan lebih baik, karena memilki bank data (tambahan penulis) sebagai sasaran pemanfaatan yang lebih memadai. ${ }^{13}$

6. Agar tidak subyketif.

7. Obyektif professional.

8. Dana terhimpun akan menjadi lebih maksimal.

${ }^{11}$ Didin Hafifuddin, Islam Aplkatif, (Jakarta: Gema Insani Press, 2003), Cet. Ke-1, 95.

12 Ibid, 96.

13 Mohammad Daud Ali, Sistem Ekonomi Islam: Zakat dan Wakaf, (Jakarta: UI Press, 1998), 30. 
82 Anis Tyas Kuncoro

9. Implementasi dan penembangan berbagai program pemberdayaan akan dapat lebih fokus untuk dilaksanakan. ${ }^{14}$

Dalam pada itu, agar pelaksanaan zakat dapat dikoordinasikan dan diarahkan secara tepat, utamanya dalam memantapkan kepercayaan masyarakat dan wajib zakat sehingga kedudukan suatu lembaga zakat tetap dapat eksis adalah senantiasa mengedepankan integritas kejujuran dengan clean and good corporate, transparan, tidak terjebak pada conflict of interest and kreatif. ${ }^{15}$

Sedang terkait dngan tujuan dan urgensi zakat, maka sesungguhnya eksistensi lembaga zakat bertumpu pada 2 (dua) aktifitas utama, yaitu:

\section{Pola Penghimpunan Zakat}

Dalam hal penghimpunan zakat, hal mendasar yang menjadi penggarapannya adalah terletak pada aspek strategi penggalangan dana zakat atau zakat raising. Berbeda dengan pola penggalangan dana di masa lalu yang cenderung pasif, menunggu dana datang dengan sendirinya, tidak sistematis dan dikerjakan oleh lembaga kepanitiaan yang dibentuk secara incidental dan temporer, maka dalam perkembangannya saat ini, pola penggalangan dana zakat atau zakat raising cenderung lebih aktif, sistematis, dan kreatif diselenggarakan oleh badan atau lembaga zakat yang dikelola dalam sebuah sistem manajemen yang integrative dan profesional. Adapun strategi dan implementasinya diarahkan pada 3 (tiga) cara, yaitu:

a. Sosialisasi zakat, yang ditunjukan untuk meningkatkan pemahaman masyarakat terhadap konsepsi zakat serta kesadarannya terhadap potensi zakat jika dikelola dengan baik, hal demikian misalnya dapat dilakukan melalui penerapan strategi marketing (pemasaran),

${ }^{14}$ Eri Sudewo, Manajemen Zakat: Tannggalkan 15 Tradisi dan Terapkan 4 Prinsip Dasar, (Ciputat: Institut Manajemen Zakat, 2004), Cet. Ke-1, XXXXVI. 15 Ibid., 24.

ulul albab: Jurnal Studi dan Penelitian Hukum Islam 
Zakat: Katup Pengaman Keseimbangan ... $\mid 83$

kerjasama media cetak dan elektronik, kegiatan malam amal, seminar, diskusi, audiensi, penyuluhan baik dalam medium khutbah Jum'at ataupun majlis taklim dan lainlain.

b. Cara penerimaan dana zakat, yang ditunjukan untuk meningkatkan efektifitas penghimpuan dana zakat, hal demikian misalnya dapat dilakukan dengan penyediaan counter zakat di tempat-tempat strategis, kerjasama dengan pihak perbankan bahkan dapat juga dilakukan dengan cara jemput bola.

c. Inventerisasi dan pengelolaan data muzakki beserta usaha-usaha pemeliharaannya melalui komunikasi aktif, korespondensi dan pelaporan pertanggungjawaban. Dengan potensi kuantitas jumlah umat Islam yang besar serta melalui penerapan pola dan strategi yang benar lagi tepat maka dana zakat yang terhimpun, jumlahnya tentu akan menjadi lebih besar pula. Namun ke depan ketika jumlah lembaga atau organisasi pengelola zakat banyak bermunculan di berbagai wilayah dengan kualitas yang beragam serta tingkat kesadaran dan pemahaman masyarakat yang cukup signifikan terhadap kewajiban zakat, maka diperlukan suatu regulasi yang dapat mengatur secara mengikat, memberikan sangsi terhadap pengelolaan yang tidak amanah, dan juga ditujukan kepada para muzakki yang enggan menunakan kewajibannya. Jika hal demikian dapat diwujukan, maka potensi zakat sebagai wujud komitmen Islam terhadap kesejahteraan dan keadilan sosial akan berdayaguna dan berhasilguna.

\section{Pola Pendayagunaan Zakat}

Pendayagunaan di sini terkait dengan upaya lembaga dalam memanfaatkan potensi zakat dan pendistribusiannya. Sesuai dengan ketentuan syari'ah, sasaran pendayagunaan ini diarahkan pada mustahik yang tergolong dalam kategori 
$84 \mid$ Anis Tyas Kuncoro

delapan ashnaf, yaitu kaum fakir, kaum msikin, muallaf, firriqab ghorim, sabilillah dan ibnu sabil. Dan kedepalan ashnaf tersebut senantiasa terbuka adanya upaya interpretasi kontekstual dengan analogi-analogi rasional sehingga menjadi relevan dengan kondisi masyarakat modern dan dapat memberikan solusi tepat terhadap problematika umat sekarang ini, khususnya pada masalah kemiskinan. Bertitik tolak dari kerangka pikir yang demikian, maka dalam perkembangannya, pola pendayagunaan zakat dapat digolongkan kedalam 4 (empat) kategori, yaitu:

a. Konsumtif tradisional, yakni dana zakat dimanfaatkan dan digunakan langsung oleh mustahik untuk pemenuhan kebutuhan hidup.

b. Konsumtif kreatif, yakni dana zakat diwujudkan dalam bentuk lain dari jenis barang semula, misalnya alat-alat sekolah, beasiswa, dan lain-lain.

c. Produktif tradisional, yakni dana zakat diberikan dalam bentuk barang-barang produksi, seperti saprodi (sarana, produksi pertanian), sapi mesin jahit, alat-alat pertukangan dan lain-lain.

d. Produktif kreatif, yakni dana zakat diwujudukan dalam bentuk modal, baik untuk membangun suatu proyek sosial maupun menambah bagi pedagan atau pengusaha kecil.

Singkatnya adalah bahwa esensi zakat sebagai sumber daya finansial yang besar, yang sesuai dengan tujuan syari'at dan tujuan sosial akan dapat dirasakan nilai gunanya yang optimal bagi umat, jika pendayagunaannya berbasis pada asa manfaat dan produktifitas.

Dalam implementasinya, pendayagunaan dana zakat harus berorientasi pada penanganan kesejahteraan sosial dan pengentasan kemiskinan baik dalam jangka pendek maupun angka panjang. Diantaranya adalah melalui pemberdayaan ekonomi, pengembangan sumber daya insani dan pemberian 
Zakat: Katup Pengaman Keseimbangan ... $\mid 85$

karitas. Yang demikian adalah sangat memungkinkan, disamping menguatnya isu masyarakat madani (civil society) yang menitikberatkan pada peningkatan peran aktif masyarakat dalam program pembangunan, maka zakat memiliki peran dan peluang lebih mamadai dalam mwujudkan tantanan sosial ekonomi yang bertumpu pada sistem distribusi yang adil dan solidaritas tinggi terhadap kaum dhu'afa.

Pemberitahuan zakat atas kaum muslimin di masa awal Islam atau pada periode Mekah lebih dilandaskan pada 3 (tiga) pijakan yaitu: ${ }^{16}$

1. Bentuk keprihatinan terhadap berbagai bentuk ketimpangan dan kesenjangan sosial antara orang-orang kaya dan miskin di kota Mekah yang disebabkan oleh gaya hidup hedonistik dan individualistik sebagai akibat dari cara pandang yang salah atas kepemilikan harta.

2. Rendahnya tingkat solidaritas sosial di kalangan masyarakat kaya Mekah.

3. Sabagai upaya untuk menyelamatkan tatanan masyarakat Mekah dari kehancuran yang diakibatkan oleh bencana sosial.

Dalam perkembangannya, pada periode Madinah, kewajiban zakat disyari'atkan atas umat Islam berbarengan dengan beberapa upaya yang dirintis oleh Rasulullah SAW dalam menentukan dasar-dasar yang kuat dalam pembentukan tatanan masyarakat muslim, meliputi bidang politik, sosial, keamanan, ekonomi dan lain-lain. ${ }^{17}$

Fungsi zakat yang pada awalnya hanya merupakan wujud empati kepada kaum dhua'fa dan bersifat sukarela, maka pada periode Madinah, fungsi zakat berubah menjadi sumber pendapatan yang paling utama bagi negara yang baru dibentuk oleh Rasulullah, dan dalan prakteknya tidak diberlakukan

${ }^{16}$ Asghar Ali Engineer, Asal Ushul dan Perkembangan Islam, terj. Imam Baihaqi, (Yogyakarta: Pustakan Pelajar, 1999), cet. Ke-1, 86-90.

17 Ibid., 88. 
$86 \mid$ Anis Tyas Kuncoro

seperti pajak, karena zakat dan pajak adalah dua hal yang berbeda. ${ }^{18}$

Dalam dunia modern, zakat adalah poros dan pusat keuangan negara. Zakat bukan hanya sekedar bentuk ibadah yang mengandung muatan moral belaka sehingga dapat mengikis gaya hidup hedonisme dan konsumerisme dikalangan kaum kaya (aghniya'), solidaritas sosial dan persaudaraan dikalangan umat. Namun lebih dari itu, zakat memiliki fungsi yang strategis dalam konteks sistem ekonomi, yaitu sebagai salah satu instrument distribusi pemerataan harta kekayaan sehingga kesenjangan dapat dieliminir dan kemiskinan dapat dientaskan. Paling tidak, dalam tataran praktis sederhana zakat dapat difungsikan sebagai katup pengaman yang memelihara keseimbangan kehidupan sosial-ekonomi umat baik yang miskin maupun yang kaya.

\section{Kesimpulan}

Melalui pemahaman yang tepat, fungsi yang secara personal sekedar dianggap superfisial dan karitatif menjadi begitu tidak terpisahkan dari pola distribusi dan pembangaunan ekonomi umat. Dengan kesadaran yang sedemikian rupa, zakat akan ditempatkan bukan hanya dalam tataran individu tapi sudah menjadi bagian dari persoalan komunal. Karenanya, dalam pelaksanaan pengelolaan zakat tidak boleh sekedar mengandalkan kesadaran personal tapi juga harus mengandung campur tangan komunal, dalam hal ini yang layak lebih berperan adalah negara dan pemerintah.

Bahkan untuk mendorong keberhasilan pelaksanaan pengelolaan zakat yang masksimal, pendekatan kepada muzakki tidak lagi hanya bersifat persuasif, tapi juga represif

18 Adiwarman Karim, Sejarah Pemikiran Ekonomi Islam, (Jakarta: IIIT, 2002), cet. Ke-2, 34 .

ulul albab: Jurnal Studi dan Penelitian Hukum Islam 
Zakat: Katup Pengaman Keseimbangan ... $\mid 87$

dan sistemik dan institusi yang pantas serta memiliki kemampuan untuk itu tidak lain adalah negara dan pemerintah.

\section{Daftar Pustaka}

Ali, Mohammad Daud. 1998. Sistem Ekonomi Islam: Zakat dan Wakaf. Jakarta: UI Press.

BAZIS DKI Jakarta. 1978. Pedoman Pelaksanaan Zakat. Hasil Penelitian dan Seminar Zakat DKI Jakarta.

Chapra, M. Umer. 2000. The Future of Economics: an Islamic Perspective. Leicester: The Islamic Foundation.

Ditjen Bimas dan Urusan Haji Depag RI. 1999. UU RI Nomor 38 Tahun 1999 tentnag Pengelola Zakat. Jakarta.

Fatwa, AM., dkk. 2004. Problematika Kemiskinan: Zakat sebagai Solusi Alternatif. Jakarta: Penerbit Belantika.

Hafifuddin, Didin. 2003. Islam Aplikatif. Jakarta: Gema Insani Press.

Kahf, Monzer. 2000. Ekonomi Islam: Telaah Analitik terhadap Fungsi Sistem Ekonomi Islam, (terj. Machnun Husein). Yogyakarta: Aditya Media.

Mas'udi, F. Masdar. 2005. Menggagas Ulang Zakat sebagai Etika Pajak dan Belanja Negara untuk Rakyat. Bandung: Mizan.

Muhammad, dan Ridwan, Mas'ud. 2005. Zakat dan Kemiskinan, Instrument Pemberdayaan Ekonomi Umat. Yogyakarta: UI Press.

Qardhaqi, Yusuf. 1991. Fiqh al-Zakat. Beirut: Mu'assasah Risalah. Raharjo, M. Dawam. "Zakat dalam Perspektif Sosial Ekonomi”, Jurnal Pesantren, No. 2/Vol.III/1986.

Sudewo, Eri. 2004. Manajemen Zakat: Tinggalkan Limabelas Tradisi dan Terapkan Empat Prinsip Dasar. Ciputat: Institut Manajemen Zakat. 